\title{
ATENDIMENTO EDUCACIONAL ESPECIALIZADO: REFLEXÕES DA REALIDADE DE UM MUNICÍPIO PAULISTA
}

\author{
Taísa Grasiela Gomes Liduenha GONÇALVES ${ }^{1}$ \\ Juliana Vechetti MANTOVANI ${ }^{2}$ \\ Ana Carolina MACALLI ${ }^{3}$
}

RESUMO: O objetivo deste artigo foi analisar o Atendimento Educacional Especializado (AEE) no Brasil, região sudeste, estado de São Paulo, especificamente, em um município paulista. Para tanto, utilizou-se as legislações que norteiam o trabalho pedagógico dentro deste espaço, os indicadores sociais oficiais e dados empíricos construídos durante as visitas ao município, quando foi realizada a observação na sala de recursos e uma entrevista com a professora responsável pelo atendimento. Os resultados indicam: ampliação no número de turmas que oferecem o AEE nas escolas brasileiras, na região sudeste e no estado de São Paulo; com relação ao município analisado constatou-se que o trabalho docente no AEE é isolado do contexto escolar e que o serviço é direcionado para os alunos com deficiência mental, embora tenha a presença de alunos com outras deficiências na escola, além disso, o atendimento limitase a atividades de vida autônoma, sobretudo, no desenvolvimento de processos mentais. Os achados mostram que ainda existem dificuldades na implementação do AEE na escola que carecem de ações mais diretivas e baseadas nas realidades municipais.

PALAVRAS-CHAVE: Atendimento educacional especializado. Educação especial. Indicadores sociais.

\section{INTRODUÇÃO}

O Atendimento Educacional Especializado (AEE) é um tema de tensão e de grande importância para a educação escolar e para a educação especial. Tem sido debatido em diferentes espaços, pois existem muitos aspectos de sua implementação que carecem de direção e esclarecimento. Assim, o presente artigo discute o Atendimento Educacional Especializado a partir da legislação vigente e, em seguida, traz algumas discussões sobre a sala de recurso, que faz parte do AEE. A pesquisa foi feita em um município do estado de São Paulo a partir da realidade de uma professora e dos indicadores educacionais.

\footnotetext{
${ }^{1}$ Doutorado em Educação Especial. UFSCar - Universidade Federal de São Carlos. Centro de Educação e Ciências Humanas. São Carlos - SP - Brasil. 13565-905. Professora na UNOPAR - Universidade Norte do Paraná. Programa de Mestrado em Metodologias para o Ensino de Linguagens e suas Tecnologias. Londrina - PR - Brasil. 86041-120 - taisaliduenha@ hotmail.com.

${ }^{2}$ Doutorado em Educação Especial. UFSCar - Universidade Federal de São Carlos. Centro de Educação e Ciências Humanas. São Carlos - SP - Brasil. 13565-905 - julianavmto@bol.com.br.

${ }^{3}$ Mestranda em Educação Especial. Bolsista da Capes. UFSCar - Universidade Federal de São Carlos. Centro de Educação e Ciências Humanas. São Carlos - SP - Brasil. 13565-905 anacarolinamacalli@hotmail.com.
} 
A articulação do AEE com o ensino comum traz consigo diferentes desafios, envolve a formação e a condição de trabalho dos docentes, a estrutura e dinâmica escolar, as práticas pedagógicas, além do real investimento para a execução de um trabalho pedagógico que garanta a apropriação do conhecimento. A educação escolar oferecida aos alunos com deficiência deve contar com todo suporte legal, financeiro, material e humano necessários à permanência e apropriação dos conteúdos escolares.

A partir do exposto, apresenta-se o AEE com base na legislação.

\section{ATENDIMENTO EDUCACIONAL ESPECIALIZADO NA LEGISLAÇÃO}

Este trabalho parte da perspectiva marxista, em que a história é essencial para a compreensão da realidade. Nesta direção, Saviani (2011, p.10) salienta que “[...] as transformações históricas determinam a educação e, ao mesmo tempo, são por ela determinadas". Desta forma, retomamos marcos políticos da Educação Especial referentes ao AEE, haja vista que esse serviço pode ser considerado um dos grandes desafios impostos aos profissionais da educação, principalmente quando se discute sua articulação com o ensino comum.

A Constituição Federal de 1988, no artigo 208, III, afirma que "[...] o dever do Estado com a educação será efetivado mediante a garantia de atendimento educacional especializado aos portadores de deficiência, preferencialmente na rede regular de ensino" (BRASIL, 1988). Neste período não havia um respaldo legal, prático e nem teórico para a realização do AEE. Além disso, a palavra "preferencialmente" tem um sentido dúbio, deixando para as instâncias escolares e/ou familiares decidirem sobre o lócus das ações pedagógicas destinadas aos alunos com deficiências.

A Política Nacional da Educação Especial na Perspectiva da Educação Inclusiva (BRASIL, 2008a) apresenta, no item IV, o objetivo da Educação Especial:

[...] o acesso, a participação e a aprendizagem dos alunos com deficiência, transtornos globais do desenvolvimento e altas habilidades/superdotação nas escolas regulares, orientando os sistemas de ensino para promover respostas às necessidades educacionais especiais. (BRASIL, 2008a, p.8).

O AEE aparece como um dos meios para se atingir tais objetivos. Nas Diretrizes da Política Nacional de Educação Especial na Perspectiva da Educação Inclusiva consta que a função do AEE é “[...] identificar, elaborar e organizar recursos pedagógicos e de 
acessibilidade que eliminem as barreiras para a plena participação dos alunos, considerando suas necessidades específicas" (BRASIL, 2008a, p.10) - ou seja, a produção de atividades e providência de materiais pedagógicos que oportunizem ao aluno com deficiência a apropriação do conteúdo. Quanto às atividades a serem realizadas durante o AEE, o documento esclarece que:

[...] diferenciam-se daquelas realizadas na sala de aula comum, não sendo substitutivas à escolarização. [...] Dentre as atividades de atendimento educacional especializado são disponibilizados programas de enriquecimento curricular, o ensino de linguagens e códigos específicos de comunicação e sinalização e tecnologia assistiva. Ao longo de todo o processo de escolarização esse atendimento deve estar articulado com a proposta pedagógica do ensino comum. (BRASIL, 2008a, p.10).

Destas colocações emergem muitas problematizações, como por exemplo: se as atividades realizadas no AEE não podem ser as mesmas realizadas na sala de aula, não poderiam ser uma continuidade das mesmas, ou uma adaptação do que vem sendo trabalhado em sala? Qual seria a relação do AEE com o currículo escolar? Será que não corremos o risco de estarmos realizando atendimentos "terapeutizados" na escola? Essas e outras questões nos levam à consideração de que há um longo caminho para a delimitação e estruturação desse serviço para que ele atenda o seu objetivo principal, qual seja, ser um suporte para que os alunos com necessidades educacionais especiais se mantenham incluídos no ensino regular e tenham sucesso acadêmico.

Mais adiante, o documento fala sobre as possibilidades de trabalho do AEE nas especificidades de cada necessidade educacional especial, ressaltando que

$\mathrm{O}$ atendimento educacional especializado é realizado mediante a atuação de profissionais com conhecimentos específicos no ensino da Língua Brasileira de Sinais, da Língua Portuguesa na modalidade escrita como segunda língua, do sistema Braille, do Soroban, da orientação e mobilidade, das atividades de vida autônoma, da comunicação alternativa, do desenvolvimento dos processos mentais superiores, dos programas de enriquecimento curricular, da adequação e produção de materiais didáticos e pedagógicos, da utilização de recursos ópticos e não ópticos, da tecnologia assistiva e outros. (BRASIL, 2008a, p.11).

Isto nos reporta a outra questão: qual a formação docente necessária para a realização desse trabalho? A formação inicial e continuada dos professores e suas condições de trabalho ocupam um importante espaço nesse debate, pois estamos nos 
referindo ao trabalho pedagógico com recursos e propostas pedagógicas específicas, que requerem estudo, vivência, suporte, investimento, preparação, além do diálogo com profissionais de outras áreas do conhecimento.

O Decreto $\mathrm{n}^{\mathrm{o}}$ 6.571, de 17 de setembro de 2008, dispõe sobre o atendimento educacional especializado e seu financiamento por meio do Fundo de Manutenção e Desenvolvimento da Educação Básica e da Valorização dos Profissionais da Educação (FUNDEB). Nesse Decreto, a União se comprometia a “[...] prestar apoio técnico e financeiro aos sistemas públicos de ensino dos Estados, do Distrito Federal e dos Municípios". Além disso, apresenta como prioridade a ampliação da oferta do AEE “[...] aos alunos com deficiência, transtornos globais do desenvolvimento e altas habilidades ou superdotação matriculados na rede pública de ensino regular" (BRASIL, 2008b, art. $1^{\circ}$ ).

Porém, esse documento foi revogado pelo Decreto $\mathrm{n}^{\circ}$ 7.611, de 17 de novembro de 2011, que dispõe sobre a Educação Especial e dá outras providências. Seu $1^{\circ}$ artigo, firma que

O dever do Estado com a educação das pessoas público-alvo da educação especial será efetivado de acordo com as seguintes diretrizes:

I - garantia de um sistema educacional inclusivo em todos os níveis, sem discriminação e com base na igualdade de oportunidades;

II - aprendizado ao longo de toda a vida;

III - não exclusão do sistema educacional geral sob alegação de deficiência;

IV - garantia de ensino fundamental gratuito e compulsório, asseguradas adaptações razoáveis de acordo com as necessidades individuais;

V - oferta de apoio necessário, no âmbito do sistema educacional geral, com vistas a facilitar sua efetiva educação;

VI - adoção de medidas de apoio individualizadas e efetivas, em ambientes que maximizem o desenvolvimento acadêmico e social, de acordo com a meta de inclusão plena;

VII - oferta de educação especial preferencialmente na rede regular de ensino; e

VIII - apoio técnico e financeiro pelo Poder Público às instituições privadas sem fins lucrativos, especializadas e com atuação exclusiva em educação especial. (BRASIL, 2011a).

O inciso VII traz, novamente, a palavra preferencialmente. Ressaltamos que a não exatidão do sentido dessa palavra poderá continuar trazendo distorções quanto ao acesso do aluno com deficiência na reder regular de ensino. $\mathrm{O}$ artigo $2^{\circ}$ enfatiza que a 
Educação Especial deve garantir os serviços de apoio especializado, sendo estes serviços compreendidos como o AEE, que no Decreto, aparece definido como

$\S 1^{\circ}[\ldots]$ o conjunto de atividades, recursos de acessibilidade e pedagógicos organizados institucional e continuamente, prestado das seguintes formas:

I - complementar à formação dos estudantes com deficiência, transtornos globais do desenvolvimento, como apoio permanente e limitado no tempo e na frequência dos estudantes às salas de recursos multifuncionais; ou

II - suplementar à formação de estudantes com altas habilidades ou superdotação.

$\S 2^{\circ} \mathrm{O}$ atendimento educacional especializado deve integrar a proposta pedagógica da escola, envolver a participação da família para garantir pleno acesso e participação dos estudantes, atender às necessidades específicas das pessoas público-alvo da educação especial, e ser realizado em articulação com as demais políticas públicas. (BRASIL, 2011a).

Embora o documento faça menção ao conjunto de atividades a serem realizadas, não esclarece o que compreendem tais atividades. No artigo $3^{\circ}$ são firmados os objetivos do AEE:

I - prover condições de acesso, participação e aprendizagem no ensino regular e garantir serviços de apoio especializados de acordo com as necessidades individuais dos estudantes;

II - garantir a transversalidade das ações da educação especial no ensino regular;

III - fomentar o desenvolvimento de recursos didáticos e pedagógicos que eliminem as barreiras no processo de ensino e aprendizagem; e

IV - assegurar condições para a continuidade de estudos nos demais níveis, etapas e modalidades de ensino. (BRASIL, 2011a).

Os objetivos são amplos e abrangentes. Para serem exequíveis é preciso que haja financiamento, estrutura material e humana, além da ruptura de um modelo de educação especial segregado e medicalizado. Porém, é preciso destacar que a Educação Especial não pode se reduzir ao AEE. $\mathrm{O}$ artigo $5^{\circ}$ dispõe sobre o apoio técnico e financeiro aos sistemas públicos de ensino e as instituições:

A União prestará apoio técnico e financeiro aos sistemas públicos de ensino dos Estados, Municípios e Distrito Federal, e a instituições comunitárias, confessionais ou filantrópicas sem fins lucrativos, com a finalidade de ampliar a oferta do atendimento educacional especializado aos estudantes com deficiência, transtornos globais do 
desenvolvimento e altas habilidades ou superdotação, matriculados na rede pública de ensino regular. (BRASIL, 2011a).

A alocação e o investimento do AEE nas instituições comunitárias, confessionais ou filantrópicas sem fins lucrativos se justificam com a finalidade de ampliação da oferta desse tipo de atendimento. O parágrafo $2^{\circ}$, do artigo $5^{\circ}$, discorre sobre os aspectos que o apoio técnico e financeiro deverá contemplar:

I - aprimoramento do atendimento educacional especializado já ofertado;

II - implantação de salas de recursos multifuncionais;

III - formação continuada de professores, inclusive para o desenvolvimento da educação bilíngue para estudantes surdos ou com deficiência auditiva e do ensino do Braile para estudantes cegos ou com baixa visão;

IV - formação de gestores, educadores e demais profissionais da escola para a educação na perspectiva da educação inclusiva, particularmente na aprendizagem, na participação e na criação de vínculos interpessoais;

V - adequação arquitetônica de prédios escolares para acessibilidade;

VI - elaboração, produção e distribuição de recursos educacionais para a acessibilidade; e

VII - estruturação de núcleos de acessibilidade nas instituições federais de educação superior. (BRASIL, 2011a).

Para que todos esses aspectos sejam devidamente contemplados, há uma emergente necessidade de formação de recursos humanos, de diálogo com outros setores, ou seja, a intersetorialidade mencionada na Política Nacional da Educação Especial na Perspectiva da Educação Inclusiva (BRASIL, 2008a) e de financiamentos. Nesse sentido, Prieto (2010, p.77) alerta que “[...] as políticas públicas estão sujeitas a avanços, recuos e manutenções, bem como se configuram como campo de disputa de diferentes interesses circunscritos a referenciais econômicos, históricos, econômicos, sociais e culturais".

Com este panorama político sobre o AEE em mãos, apresenta-se a seguir este atendimento com base nos indicadores sociais.

\section{ATENDIMENTO EDUCACIONAL ESPECIALIZADO SEGUNDO OS INDICADORES SOCIAIS}

Este estudo baseia-se na abordagem marxista, com o intuito de analisar a educação desigual em nosso país. O estudo de Barroco (2011) aponta que em uma 
sociedade capitalista, a educação escolar não vem garantindo um bom ensino e adequações necessárias para as pessoas sem deficiência de classes populares. A situação se complica neste contexto social, político, econômico e educacional ao se tratar da pessoa com deficiência.

Em síntese, o objetivo da pedagogia histórico- crítica é colocar a educação em busca da transformação das relações de produção. Essa teoria defende a educação escolar, a especificidade da escola. Portanto, a escola é um espaço formal distinta do cotidiano extra-escolar, em que há uma intencionalidade e o objetivo é proporcionar aos indivíduos a socialização dos conhecimentos sistematizados (SCALCON, 2002).

Saviani (2008) aponta que os principais problemas da educação brasileira podem ser agrupados em dois grandes desafios. O primeiro, é que não conseguimos implantar um sistema de ensino em nível nacional, sendo que a educação brasileira acumula um déficit histórico centenário.

O segundo desafio é a descontinuidade. A educação escolar deve ser contínua, com uma disposição durável e irreversível, deste modo, o aluno precisa se apropriar do conhecimento escolar e desenvolver sua trajetória científica. Outro aspecto de descontinuidade ocorre nas políticas educacionais, sendo que cada governo quer deixar sua marca na história política, assim sendo, programas implementados em governos anteriores são deixados de lado (SAVIANI, 2008).

Portanto, conforme a pedagogia histórico-crítica, o processo de exclusão educacional é histórico em nosso país. Para conter a população diante desse processo histórico foram criadas políticas públicas e áreas educacionais foram fragmentadas, como é o caso da área da Educação Especial. Concorda-se com Cury (2005) e com Machado (2010) ao alegarem que as políticas que deveriam ser universais, estão se constituindo de forma focal, separando por grupos.

A Educação Especial brasileira se constituiu como filantrópica, com um sistema paralelo de ensino, distanciado da escola regular e implementado, via de regra, em espaços segregados tais como as instituições e classes especiais (BUENO, 1993).

Historicamente, a Educação Especial garantiu a oferta de escolaridade para as pessoas com deficiência em nossa sociedade, ao mesmo tempo em que se consolidou como instrumento básico para sua segregação (BUENO, 1993).

A partir desse panorama da Educação Especial em nosso país, o intuito deste estudo é analisar a situação do AEE para os alunos com deficiência, por possibilitar a apropriação do conhecimento científico, artístico e filosófico, propostos por Saviani 
(2012), essenciais para a formação do homem integral. Para tanto, será analisado os indicadores sociais.

Compreende-se a análise dos indicadores sociais na perspectiva crítica, em que as dimensões de qualidade e quantidade compõem uma unidade. Ferraro (2012) afirma que nessa abordagem “[...] não há quantidade sem qualidade, nem qualidade sem quantidade, a unidade entre essas duas dimensões do real está em sua inseparabilidade ou exigência recíproca, não em qualquer identidade imaginária entre ambas" (FERRARO, 2012, p. 144).

Ainda, segundo o autor, esta perspectiva, afasta-se das concepções opostas e complementares entre quantidade e qualidade.

[...] o entendimento de que a dialética marxista (a dialética posta "de cabeça para cima", ou com os pés no chão, na perspectiva do materialismo histórico, com destaque para Marx e Gramsci) se constitui em caminho promissor para poder avançar na discussão da relação entre quantidade e qualidade na pesquisa, tanto nas ciências sociais em geral, quanto na educação em particular. (FERRARO, 2012, p.143).

A dialética na perspectiva marxista não é excludente ao tratar de quantidade e qualidade; ao contrário, supera essa discussão dos opostos, e, defende a unidade indissolúvel. Portanto, não podemos desconsiderar que "[...] a raiz dessa unidade reside a prática social dos homens, tecida historicamente pelos entrelaçamentos de subjetividades. Disso resulta inclusive, a impossibilidade de juízos neutros na construção do conhecimento [...]" (MARTINS, 2006, p.15-16).

Nesta perspectiva teórica, analisam-se os indicadores sociais, especificamente o censo escolar, pois a partir deles as políticas públicas são planejadas e executadas, para assim “[...] traduzirem em cifras tangíveis e operacionais várias das dimensões relevantes, específicas e dinâmicas da realidade social” (JANNUZZI, 2005, p.138).

Deste modo, os indicadores sociais são essenciais para o planejamento público, formulação e avaliação de políticas sociais, além disso, possibilitam que poder público e sociedade civil averiguem as condições de vida da população e permitem uma investigação acadêmica sobre a mudança social e sobre os determinantes dos fenômenos sociais (JANNUZZI, 2002).

Segundo Moreira (2008), a utilização de indicadores tem ganhado espaço e servido de instrumento para balizar a distribuição de recursos, caminhando para 
transformarem-se em ferramenta de monitoramento das políticas públicas no país. Gatti (2004), ao discutir os estudos quantitativos em educação, afirma que existem problemas educacionais que necessitam ser qualificados por quantificações para sua contextualização e compreensão. A autora ainda sublinha que o uso da base de dados existentes sobre educação é muito pequeno, o que revela a necessidade e a importância de se analisar os dados censitários disponibilizados.

Um indicador da realidade educacional é o censo escolar, pois se trata de um levantamento de dados estatístico-educacionais de âmbito nacional realizado todos os anos e coordenado pelo Instituto Nacional de Estudos e Pesquisas Educacionais Anísio Teixeira (INEP) vinculado ao Ministério da Educação (MEC). Ele é feito com a colaboração das Secretarias Estaduais e Municipais de Educação e com a participação de todas as escolas públicas e privadas do país. Trata-se do principal instrumento de coleta de informações da educação básica, que abrange as suas diferentes etapas e modalidades. O censo escolar coleta dados sobre estabelecimentos, matrículas, funções docentes, movimento e rendimento escolar ${ }^{4}$.

Os dados referentes ao censo escolar se encontram no site do INEP para download e necessitam de softwares específicos para a leitura dos dados.

O censo escolar apresenta quatro bancos de dados: turma, escola, docente e matrículas. Este trabalho focou-se no banco de dados de turma e de matrículas do censo escolar. Os dados de turma foram agregados segundo a variável ${ }^{5}$ : Tipo de Atendimento (Atendimento Educacional Especializado). No banco de dados de matrículas verificouse o tipo de deficiência (visual, auditiva, física e mental). Para a leitura e tratamento estatístico dos microdados da Educação Básica utilizei o Software IBM SPSS (Statistical Package for the Social Sciences).

O ano inicial de 2009 foi delimitado como período de análise do censo escolar por ter sido após o estabelecimento da Política Nacional de Educação Especial na Perspectiva da Educação Inclusiva Brasil (BRASIL, 2008a), implantada pela Secretaria de Educação Especial do Ministério da Educação, em 2008. O último ano analisado do Censo Escolar da Educação Básica (BRASIL, 2012) foi 2012, por apresentar os dados mais atuais no momento da realização deste estudo.

\footnotetext{
4 Informações do site do INEP. Disponível em: <http://portal.inep.gov.br/web/educacenso/censoescolar>. Acesso em: 4 abr. 2016.

${ }^{5}$ As nomenclaturas das variáveis estão de acordo com o caderno de instruções do INEP.
} 
Na sequência da análise, verificaram-se os dados referentes às turmas por tipo de AEE, que se organizam da seguinte maneira: Sistema Braile; Atividades de vida autônoma; Recursos para alunos com baixa visão; Desenvolvimento de processos mentais; Orientação e mobilidade; Língua Brasileira de Sinais; Comunicação alternativa e aumentativa; Atividades de enriquecimento curricular; Soroban; Informática acessível e Língua Portuguesa na modalidade escrita.

Em paralelo ao estudo dos dados do Censo Escolar, analisou-se dados da realidade educacional de um município paulista, sobretudo referente ao AEE, a partir de observações e registros sobre a sala de recursos e uma entrevista com a professora responsável pelo atendimento a partir de um roteiro de questões. A entrevista descrita não foi gravada, mas as informações disponibilizadas pela professora foram registradas em um diário de campo.

As análises dos microdados sobre as turmas que oferecem o AEE permitiram apresentar resultados sobre a situação deste serviço destinado às pessoas com necessidades educacionais especiais na educação brasileira. Considera-se que o primeiro passo é cotejar o número de turmas de AEE com o total de turmas na educação básica no Brasil, região sudeste e estado de São Paulo, demonstrado na Tabela 1.

Tabela 1 - Número de turmas de Atendimento Educacional Especializado

\begin{tabular}{lllllllll}
\hline \multirow{2}{*}{ Ano } & $\begin{array}{l}\text { Total de turmas na } \\
\text { Educação Básica }\end{array}$ & $\begin{array}{l}\text { Turmas de AEE } \\
\text { no Brasil }\end{array}$ & $\%$ & $\begin{array}{l}\text { Turmas de } \\
\text { AEE Sudeste }\end{array}$ & $\%$ & $\begin{array}{l}\text { Turmas de AEE } \\
\text { São Paulo }\end{array}$ & $\%$ \\
\hline 2009 & 2.254 .968 & 18.458 & 0,8 & 6.037 & 32,7 & 3.062 & 50,7 \\
2010 & 2.301 .077 & 28.034 & 1,2 & 8.854 & 31,6 & 3.993 & 45,1 \\
2011 & 2.356 .492 & 40.505 & 1,7 & 12.734 & 31,4 & 6.086 & 47,8 \\
2012 & 2.422 .680 & 53.079 & 2,2 & 16.721 & 31,5 & 7.237 & 43,3
\end{tabular}

Fonte: Elaboração própria com base no censo escolar da Educação Básica: microdados do MEC/ INEP (BRASIL, 2009b, 2010, 2011b, 2012).

O primeiro dado a apontar é que em uma turma de AEE pode-se se ofertar diversos tipos de atendimentos. De acordo com a tabela 1, o número de turmas de AEE no Brasil apresenta uma tendência crescente; ao cotejar o ano de 2012 com 2009, notase um aumento de 65,2\% no número de turmas. Verifica-se que a turma de AEE no período analisado corresponde a uma média de 1,5\% das turmas totais da educação básica do Brasil.

A região sudeste corresponde, em média, a 31,8\% das turmas de AEE do Brasil. O estado de São Paulo representa, em média, 46,7\% das turmas de AEE da região 
sudeste. A mesma disposição de ampliação nas turmas de AEE ocorre na região sudeste e estado de São Paulo. Isto indica que Política Nacional da Educação Especial na Perspectiva da Educação Inclusiva (BRASIL, 2008a) interferiu no meio educacional. Entretanto, questiona-se se as práticas adotadas no AEE estão de acordo com a legislação.

\section{O ATENDIMENTO EDUCACIONAL ESPECIALIZADO EM UM MUNICÍPIO PAULISTA}

De acordo com o IBGE (2010), a população do município paulista estudado corresponde a aproximadamente 8.500 habitantes. Sua economia baseia-se na cultura da cana-de-açúcar. Ainda conforme os dados do IBGE (2010), a cidade possui 3 escolas de ensino fundamental, uma de ensino médio e uma de pré-escola; nessas escolas trabalha um contingente de 106 docentes (63 no ensino fundamental, 31 no médio e 12 na préescola).

Neste município há apenas uma sala de recursos, criada em 2009 e localizada em uma escola municipal de ensino regular que atende alunos do campo e da cidade. Até o momento da pesquisa a sala recursos era do tipo 1, pois atendia somente a alunos com um tipo de deficiência - a deficiência mental. Há apenas uma professora na sala de recurso, que reside em outro município e se desloca todos os dias da semana. Ela tem formação em licenciatura plena em pedagogia com habilitação para o ensino de deficientes mentais. A professora atua, exclusivamente, nesta área há 12 anos. A sala de recursos do município possui diversos materiais, entretanto, a professora destaca que encontra dificuldade nas barreiras arquitetônicas e atitudinais. Os atendimentos são organizados por até 3 vezes na semana, com a duração de uma hora ou até duas horas, dependendo da necessidade de cada aluno.

O Projeto Político Pedagógico (PPP) da escola do município que possui a sala de recursos não foi disponibilizado integralmente, mas a parte que pôde ser analisada não contemplava nenhum aspecto sobre o AEE, existente ali desde o ano de 2009. A diretora, ao ser questionada sobre o documento, informou que o PPP de 2012 ainda está sendo elaborado, e nele serão integradas as normativas sobre Educação Especial, Atendimento Educacional Especializado e Sala de Recursos. De acordo com a Resolução $\mathrm{n}^{\circ} 4$ do Conselho Nacional de Educação/Câmara de Educação Básica (CNE/CEB) de 02 de outubro de 2009 (BRASIL, 2009a), o artigo 10 dispõe que o PPP 
da escola de ensino regular deve institucionalizar a oferta do AEE prevendo também sua organização; a escola ainda não se enquadrou nessas normas.

A sala de recurso da escola visitada ainda não se configura como uma sala de recursos multifuncionais, destinando-se apenas ao atendimento de alunos com deficiência intelectual. Este atendimento específico para um determinado tipo de deficiência configurou-se até o ano de 2008, mas atualmente a Sala de Recurso da escola não coloca em vigor a legislação (BRASIL, 2008b), o que resulta em segregação para os demais alunos da escola que necessitam deste atendimento educacional especializado. Bruno (2010) alerta para a organização do AEE baseada na sala de recurso multifuncional. Para a autora,

\begin{abstract}
Observa-se a desconstrução de outras formas alternativas de atendimento educacional especializado como: o apoio e suporte ao professor e ao aluno na classe comum; o apoio e suporte às famílias; as salas de recursos para a intervenção educacional precoce; a educação para o trabalho; o espaço para as Atividades de Vida Autônoma e de Orientação e Mobilidade. (BRUNO, 2010, p.7).
\end{abstract}

Ainda conforme essa autora, atividades importantes para o desenvolvimento humano e aprendizagem desaparecem quando o AEE se constitui de forma redutora como a sala de recurso multifuncional. O trabalho da educação especial não se limita ao AEE e nem ao espaço circunscrito da sala de aula.

Após a mostra sobre a tensão da AEE enquanto sala de recurso ou sala de recurso multifuncional, a Tabela 2 apresenta as matrículas de alunos com necessidades educacionais especiais no município paulista.

Tabela 2 - Número de matrículas no município

\begin{tabular}{lllllll}
\hline Ano & $\begin{array}{l}\text { Total de matrículas da } \\
\text { Educação Básica }\end{array}$ & NEE* & $\begin{array}{l}\text { Deficiência } \\
\text { visual }\end{array}$ & $\begin{array}{l}\text { Deficiência } \\
\text { auditiva }\end{array}$ & $\begin{array}{l}\text { Deficiência } \\
\text { física }\end{array}$ & $\begin{array}{l}\text { Deficiência } \\
\text { mental }\end{array}$ \\
\hline 2009 & 2.146 & 32 & 0 & 2 & 1 & 29 \\
2010 & 2.139 & 37 & 1 & 2 & 0 & 34 \\
2011 & 2.047 & 46 & 0 & 1 & 1 & 44 \\
2012 & 2.071 & 48 & 0 & 1 & 0 & 47
\end{tabular}

$* \mathrm{NEE}=$ Necessidades Educacionais Especiais

Fonte: Elaboração própria com base no censo escolar da Educação Básica: microdados do MEC/ INEP (BRASIL, 2009b, 2010, 2011b, 2012).

Conforme podemos observar na Tabela 2, as matrículas da educação básica do município apresentaram uma redução; cotejando-se o ano de 2012 com 2009, verifica-se 
uma queda de 3,5\% nas matrículas. Os dados indicam aumentos consecutivos, no período, no número de matrículas de alunos com NEE.

Um destaque é o número elevado de matrículas de deficiência mental em todos os anos. Um assunto que merece atenção, pois se especula a questão do diagnóstico, já que é difícil encontrar um parecer que confirme a deficiência, e dos julgamentos errôneos dos profissionais, que acabam classificando alunos com problemas comportamentais e dificuldades de aprendizagem. Outro fator é a dificuldade que os responsáveis das instituições escolares encontram durante o preenchimento do censo escolar. A falta de conhecimento é a principal delas, como por exemplo o profissional não ter clareza sobre o diagnóstico do aluno, ou em qual categoria de deficiência se encaixam as opções do formulário do censo escolar. Estas dificuldades resultam em classificações aleatórias. De fato, segundo dados de uma pesquisa desenvolvida em municípios do interior do estado de São Paulo (VELTRONE, 2011), muitos educadores relataram dificuldades para identificar com precisão a deficiência, pois ainda se mesclam as dificuldades de aprendizagem aos problemas de comportamento.

Ao tratar das matrículas de alunos com deficiência, a direção da escola explicou sobre o preenchimento do censo escolar, e também sobre a dupla matrícula. Segundo a diretora, os alunos que recebem o atendimento educacional especializado na escola e que estão matriculados no ensino regular têm garantido o repasse de recursos do Fundo de Manutenção e Desenvolvimento da Educação Básica e de Valorização dos Profissionais da Educação (Fundeb) duplicado. Esta é uma realidade que está legalizada no decreto $\mathrm{n}^{\mathrm{o}} 7.611$, de novembro de 2011 , artigos $8^{\circ}$ e $9^{\circ}$ :

Art. $8^{\circ}$ - O Decreto no 6.253, de 2007, passa a vigorar com as seguintes alterações:

Art. 9'-A. - Para efeito da distribuição dos recursos do FUNDEB, será admitida a dupla matrícula dos estudantes da educação regular da rede pública que recebem atendimento educacional especializado.

$\S 1^{\circ}$ - A dupla matrícula implica o cômputo do estudante tanto na educação regular da rede pública, quanto no atendimento educacional especializado.

$\S 2^{\circ}$ - O atendimento educacional especializado aos estudantes da rede pública de ensino regular poderá ser oferecido pelos sistemas públicos de ensino ou por instituições comunitárias, confessionais ou filantrópicas sem fins lucrativos, com atuação exclusiva na educação especial, conveniadas com o Poder Executivo competente, sem prejuízo do disposto no art. 14". (BRASIL, 2011a). 
Os dados educacionais de cada município estão vinculados a interesses apontados pela própria política; deste modo, o preenchimento do censo escolar é de relevância para as escolas, sobretudo para a obtenção de recursos públicos.

Com base no número de matrículas de alunos com necessidades educacionais especiais da educação básica no município apresenta-se o número de turmas atendidas no município paulista, segundo o tipo de Atendimento Educacional Especializado, demonstrado na Tabela 3.

Tabela 3 - Número de turmas por tipo de Atendimento Educacional Especializado no município

\begin{tabular}{lllll}
\hline $\begin{array}{l}\text { Tipo de Atendimento Educacional } \\
\text { Especializado }\end{array}$ & Ano & & & \\
\cline { 2 - 5 } & 2009 & 2010 & 2011 & 2012 \\
\hline Atividades de vida autônoma & 2 & 1 & 0 & 0 \\
Desenvolvimento de processos mentais & 2 & 1 & 1 & 1 \\
\hline
\end{tabular}

Fonte: Elaboração própria com base no censo escolar da Educação Básica: microdados do MEC/ INEP (BRASIL, 2009b, 2010, 2011b, 2012).

Apesar da tabela 2 indicar a presença de alunos com deficiências auditiva, visual e física na educação básica no município, o AEE limita-se a atividades de vida autônoma e, sobretudo, no desenvolvimento de processos mentais, que pode ser em decorrência das ações de patologização do fracasso escolar, de medicalização do ensino, da centralização das justificativas do "não aprender" apenas no aluno e da precariedade dos processos de avaliação, diagnóstico e encaminhamentos pedagógicos (ANACHE, 1997; MOYSES; COLARES, 1997; PATTO, 2001).

No município, somente nos anos de 2009 e 2010 há turmas de atividades de vida autônoma. Este dado pode ser explicado como consequência da Política de Educação Especial na Perspectiva da Educação Inclusiva (BRASIL, 2008a), que propõe a diferenciação das atividades entre o AEE daquelas realizadas na sala de aula comum. Essas atividades não podem substituir a escolarização, pois “[...] esse atendimento complementa e/ou suplementa a formação dos alunos com vistas à autonomia e independência na escola e fora dela" (BRASIL, 2008a, p.15).

Porém, cabe aqui um questionamento: como este tipo de atendimento, denominado "atividades de vida autônoma", está sendo trabalhado nos âmbitos educacionais? Este trabalho vem se constituindo em uma perspectiva pedagógica ou terapêutica medicalizadora? 
A maior dificuldade encontrada pela professora é relacionada à gestão da escola. Destaca a professora que a gestão escolar enfatiza as dificuldades e não nas potencialidades dos alunos. Outro aspecto apontado pela professora é o de não estabelecer um trabalho em conjunto com os outros professores. Ela afirma que, apesar da boa relação com eles, mantém contato com os professores uma vez por semana e com os pais uma vez por mês. Relata ainda que participa das reuniões de Hora de Trabalho Pedagógico Coletivo (HTPC), mas não das reuniões de pais e mestres.

A professora aponta, no final da entrevista:

\begin{abstract}
Gostaria de ressaltar a importância e necessidade de haver no município um centro integrado de atendimento de profissionais com psicólogos, terapeutas, fonoaudiólogos, fisioterapeutas, que atendessem e desenvolvessem um trabalho com estes alunos, e desse todo suporte para o âmbito escolar, e que fossem oferecidos cursos de aperfeiçoamento para todos os professores da sala regular. (Registro de Cатро)
\end{abstract}

Segundo o relato da professora, seu trabalho pedagógico na sala de recursos é uma forma de apoiar, complementar ou suplementar o processo de apropriação de conhecimentos das salas comuns e regulares, estabelecendo um conjunto de procedimentos específicos, de forma a desenvolver os processos cognitivos, motores e sócio-afetivo-emocionais de cada aluno atendido. Reforça também a importância desta sala não ser confundida com reforço escolar ou repetição de conteúdos programáticos da classe comum. Verifica-se que a professora tem consciência da função da sala de recurso na escola e compromisso com o trabalho pedagógico realizado.

O Atendimento Educacional Especializado não pode ser considerado o único elemento responsável pelo aprendizado do aluno com deficiência, mas sim um deles. $\mathrm{O}$ estudo revelou que ainda existem lacunas que precisam de criteriosa análise (pois há alunos com deficiências que não estão usufruindo desse direito), além da necessidade de se construir um trabalho pedagógico contextualizado no AEE. Embora haja avanços na história da Educação Especial, é preciso atenção quanto aos possíveis retrocessos, pois a lógica de uma prática pedagógica fragmentada no AEE pode anunciar a segregação dentro do contexto escolar. Além de propostas de trabalho ainda estarem vinculadas às práticas terapêuticas e institucionais.

\title{
CONSIDERAÇÕES FINAIS
}


A investigação e análise dos trabalhos pedagógicos e o modo como estão sendo estruturados os apoios educacionais especializados, no município paulista, possibilitam o desenvolvimento de um olhar mais atento, em termos de criticidade, para identificar desafios e avançar nas discussões desta área.

Nota-se que a diversidade dos contextos dos atendimentos educacionais resulta em diferentes práticas pedagógicas que acabam sendo adotadas, devido ao ambiente em que esses atendimentos são realizados. O apoio da gestão escolar, dos demais profissionais do ensino regular, a participação da família e de responsáveis, assim como a oferta de recursos, como materiais didáticos e pedagógicos e equipamentos para o desenvolvimento do trabalho do professor são fundamentais na melhoria da qualidade do atendimento. Acentuam-se os desafios vivenciados diariamente por esses profissionais quando os elementos citados acima são precários, resultando na falta de incentivo e motivação do professor para prosseguir com seu trabalho. Desta forma, acreditamos ser errôneo e ingênuo criticar apenas a prática do docente sem analisar e compreender primeiramente a realidade desse profissional. Pois a realização de seu trabalho está vinculada às condições de trabalho que possui.

Por fim, espera-se que os dados socializados colaborem para a ampliação do debate acerca do AEE nas escolas. O estudo deixa indícios de realidade que podem abrir caminhos para o aprendizado escolar do aluno com deficiência e para a realização de um trabalho pedagógico efetivamente articulado ao ensino comum. Ainda existem dificuldades na implementação do AEE na escola que carecem de ações mais diretivas e baseadas nas realidades municipais. Contudo, a luta pela melhoria das condições de ensino deve prosseguir e inquietar, para que assim o aluno com deficiência atinja o sucesso escolar.

\section{EDUCATIONAL SERVICE SPECIALIST: REALITY REFLECTION OF A MUNICIPALITY PAULISTA}


ABSTRACT: The objective of this article was to analyze the Specialized Educational Care (AEE, in Portuguese) in Brazil, southeast region, state of São Paulo, specifically in a paulista municipality. Therefore, was used the laws that guide the pedagogical work within this space, official social indicators and empirical data, which was created during visits to the city, when was realized the observation in the resource room and an interview with the responsible teacher. The results indicate: increase in the number of classes that offer the AEE in Brazilian schools, in the southeast region and in the state of São Paulo; with respect to the municipality analyzed, was found that teaching the $A E E$ is isolated from the school context and the service is directed to students with learning disabilities, although there is presence of students with other disabilities in school, in addition, the service is limited to an autonomous life activities, especially in the development of mental processes. The results showed that still there are difficulties in implementing the AEE in school that need more policies and actions based on local realities.

KEYWORDS: Specialized educational care. Special education. Social indicators.

\section{REFERÊNCIAS}

ANACHE, A. A. Diagnóstico ou Inquisição: estudo sobre o uso do diagnóstico Psicológico na Escola. 1997. Tese (Doutorado em Psicologia) - Instituto de Psicologia, Universidade de São Paulo, São Paulo, 1997.

BARROCO, S. M. S. Pedagogia histórico-crítica, psicologia histórico-cultural e educação especial: em defesa do desenvolvimento da pessoa com e sem deficiência. In: MARSIGLIA, Ana Carolina Galvão (Org.). Pedagogia histórico-crítica: 30 anos. Campinas: Autores Associados, 2011. p.169-196.

BRASIL. Ministério da Educação. Instituto Nacional de Estudos e Pesquisas Educacionais Anísio Teixeira. Censo Escolar da Educação Básica - 2012. Brasília, 2012. Disponível em:

<http://download.inep.gov.br/microdados/micro_censo_escolar_2012.zip>. Acesso em: 4 abr. 2016.

Decreto ${ }^{\circ} 7.611$, de 17 de novembro de 2011. Dispõe sobre a educação especial, o atendimento educacional especializado e dá outras providências. Diário Oficial da União, Brasília, 2011a. Disponível em:

<http://www.planalto.gov.br/ccivil_03/_ato2011-2014/2011/decreto/d7611.htm〉. Acesso em: 4 abr. 2016.

Ministério da Educação. Instituto Nacional de Estudos e Pesquisas

Educacionais Anísio Teixeira. Censo Escolar da Educação Básica - 2011. Brasília, 2011b. Disponível em:

< http://download.inep.gov.br/microdados/micro_censo_escolar_2011.zip〉. Acesso em: 4 abr. 2016.

Ministério da Educação. Instituto Nacional de Estudos e Pesquisas

Educacionais Anísio Teixeira. Censo Escolar da Educação Básica - 2010. Brasília, 2010. Disponível em: 
<http://download.inep.gov.br/microdados/micro_censo_escolar_2010.zip>. Acesso em: 4 abr. 2016.

Ministério da Educação. Conselho Nacional de Educação. Resolução no 04, de 02 de outubro de 2009. Institui as Diretrizes Operacionais para o Atendimento Educacional Especializado na Educação Básica - Modalidade Educação Especial. Diário Oficial da União, Brasília, n.190, 5 out. 2009a.

Ministério da Educação. Instituto Nacional de Estudos e Pesquisas Educacionais Anísio Teixeira. Censo Escolar da Educação Básica - 2009. Brasília, 2009b. Disponível em: <http://download.inep.gov.br/microdados/micro_censo_escolar_2009.zip>. Acesso em: 4 abr. 2016.

\section{Política Nacional da Educação Especial na Perspectiva da Educação}

Inclusiva. Brasília: MEC, 2008a.

Decreto $\mathrm{n}^{\circ}$ 6.571, de 17 de setembro de 2008. Revogado pelo Decreto $\mathrm{n}^{\circ} 7.611$, de 2011. Dispõe sobre o atendimento educacional especializado, regulamenta o parágrafo único do art. 60 da Lei $\mathrm{n}^{\circ}$ 9.394, de 20 de dezembro de 1996, e acrescenta dispositivo ao Decreto $n^{\circ}$ 6.253, de 13 de novembro de 2007. Diário Oficial da União, Brasília, 2008b. Disponível em: <http://www.planalto.gov.br/ccivil_03/_ato20072010/2008/Decreto/D6571impressao.htm>. Acesso em: 4 abr. 2016.

Constituição da República Federativa do Brasil. 1988. Disponível em: <http://www.planalto.gov.br/ccivil_03/constituicao/constitui\%C3\%A7ao.htm>. Acesso em: 18 abr. 2013.

BRUNO, M. M. G. A política pública de educação especial na perspectiva da educação inclusiva: algumas reflexões sobre as práticas discursivas e não discursivas. In: REUNIÃO ANUAL DA ANPED, 33., 2010, Caxambu, MG. Educação no Brasil: o balanço de uma década. Caxambu: ANPED, 2010. p.1-13.

BUENO, J. G. S. Educação especial brasileira: integração/ segregação do aluno diferente. São Paulo: EDUC, 1993.

CURY, C. R. J. Políticas inclusivas e compensatórias na educação básica. Cadernos de Pesquisa: revista de estudos e pesquisa em educação, São Paulo, v. 35, p. 11-32, 2005.

FERRARO, A. R. Quantidade e qualidade na pesquisa em educação, na perspectiva da dialética marxista. Pro-Posições, Campinas, v. 23, n. 1 (67), p. 129-146, jan./abr. 2012.

GATTI, B. A. Estudos quantitativos em educação. Educação e Pesquisa, São Paulo, v. 30, n. 1, p.11-30, 2004.

INSTITUTO BRASILEIRO DE GEOGRAFIA E ESTATÍSTICA [IBGE]. Sistema IBGE de Recuperação Automática: SIDRA. Brasília, 2010. Disponível em: <http://www.sidra.ibge.gov.br/bda/popul/default.asp?t=4\&>. Acesso em: 5 abr. 2016. 
JANNUZZI, P. M. Indicadores para Diagnóstico, Monitoramento e Avaliação de Programas Sociais no Brasil. Revista do Serviço Público. Brasília, v. 56, n. 2, p. 137159, 2005.

Considerações sobre o uso, mau uso e abuso dos indicadores sociais na formulação e avaliação de políticas públicas municipais. Revista de Administração Pública, Rio de Janeiro, v. 36, n. 1, p. 51-72, jan./fev. 2002.

MACHADO, M. M. Quando a obrigatoriedade afirma e nega o direito a educação. Retratos da Escola, Brasília, v. 4, p. 245-258, 2010.

MARTINS, L. M. As aparências enganam: divergências entre o materialismo histórico dialético e as abordagens qualitativas em pesquisa. In: REUNIÃO ANUAL DA

ANPED, 29., 2006. Educação, Cultura e Conhecimento: desafios e compromissos. v. 1. Caxambu: ANPED, 2006. p.1-17.

MOREIRA, J. G. Sistema de indicadores educacionais no acompanhamento e avaliação de políticas públicas. Estudos em Avaliação Educacional, São Paulo, v.19, n.41, p.408-430, set./dez. 2008. Disponível em:

<http://www.fcc.org.br/pesquisa/publicacoes/eae/arquivos/1457/1457.pdf>. Acesso em: 4 abr. 2016.

MOYSES, M. A. A.; COLLARES, C. A. L. Inteligência Abstraída, Crianças Silenciadas: as Avaliações de Inteligência. Psicologia USP, São Paulo, v. 8, p. 63, 1997.

PATTO, M. H. S. A produção do fracasso escolar: histórias de submissão e rebeldia. 2. ed. São Paulo: Casa do Psicólogo, 2001.

PRIETO, R. G. Políticas de Inclusão Escolar no Brasil: sobre novos/velhos significados para a Educação Especial. In: MENDES, E.; ALMEIDA, M. A. Das Margens ao Centro: perspectivas para as políticas e práticas educacionais no contexto da educação inclusiva. Araraquara, SP: Junqueira \& Marin, 2010. p.61-78.

SAVIANI, D. Pedagogia histórico-crítica: primeiras aproximações. 11. ed. Campinas, SP: Autores Associados, 2012.

História, Educação e Transformação: tendências e perspectivas para a educação pública no Brasil. In: LOMBARDI, J. C.; SAVIANI, D. (Org.). História, Educação e Transformação. Campinas, SP: Autores Associados, 2011. p.9-31.

Educação socialista, pedagogia histórico-crítica e os desafios da sociedade de classes. In: LOMBARDI, J.C.; SAVIANI, D. (Org.). Marxismo e Educação: debates contemporâneos. 2.ed. Campinas, SP: Autores Associados: HISTEDBR, 2008. p.223274.

SCALCON, S. À Procura da Unidade Psicopedagógica: articulando a psicologia histórico-cultural com a pedagogia histórico-crítica. v. 1. Campinas: Autores Associados, 2002. 
VELTRONE, A. A Inclusão escolar do deficiente intelectual no estado de São

Paulo: quem é este aluno e como é identificado. 193f. Tese (Doutorado em Educação

Especial - Educação do Indivíduo Especial) - Centro de Educação e Ciências Humanas, Universidade Federal de São Carlos, São Carlos, 2011. 